See discussions, stats, and author profiles for this publication at: https://www.researchgate.net/publication/333417173

\title{
Güvensiz Bağlanma Neden Yaygın? Bir Erken Uyarı ve Uzaklaşma Sistemi olarak Güvensiz Bağlanma
}

Article · December 2018

Dol: 10.31828/tpy.13019961.2018.42.02.01

CITATIONS

2 authors:

Ezgi Sakman

Cornell University

7 PUBLICATIONS 8 CITATIONS

SEE PROFILE
READS

116

Nebi Sümer

Middle East Technical University

105 PUBLICATIONS 3,011 CITATIONS

SEE PROFILE

Some of the authors of this publication are also working on these related projects:

Project Checklist of metazoon parasites recorded in Anura and Urodela from Turkey View project

Project EUROPLAT View project 


\title{
Güvensiz Bağlanma Neden Yaygın? Bir Erken Uyarı ve Uzaklaşma Sistemi olarak Güvensiz Bağlanma
}

\author{
Ezgi Sakman \\ Nebi Sümer \\ Bilkent Üniversitesi \\ Sabanc1 Üniversitesi
}

\begin{abstract}
Özet
Bağlanma yazınının güvenli bağlanmanın yararlarını, güvensiz bağlanmanın ise olumsuz sonuçlarını gösteren araştırma bulgularıyla dolu olmasına karşın, bütün kültürlerde hem çocukların hem de yetişkinlerin neredeyse yarısının güvensiz bağlandığı bilinmektedir. Bu durum bağlanma paradoksu olarak adlandırılmıştır. Bağlanmayı evrimsel açıdan ele alan ve birbirini tamamlayan iki yaklaşım, güvensiz bağlanma yönelimlerinin farklı çevresel koşullar altında ayırt edici ve uyumu kolaylaştıran bir işlev üstlendiğini öne sürerek bu paradoksu açıklamıştır. Bağlanmanın yaşam geçmişi modelleri, güvensiz bağlanmanın sert ekolojilerde artan üreme uygunluğuna vesile olabileceğini öne sürerken, sosyal savunma kuramı güvensiz bağlanmanın öngörülemeyen tehdit durumlarında grubun hayatta kalma şansını arttırdığı varsayımına dayanır. Bu derlemenin amacı güvensiz bağlanmanın hangi koşullar altında uyumlayıcı olabileceğini savlayan bu iki yaklaşımı ve bu kapsamda yapılan araştırmaları derlemek ve Türkçe yazına kazandırmaktır.
\end{abstract}

Anahtar kelimeler: Bağlanma paradoksu, güvensiz bağlanmanın işlevleri, bağlanmanın yaşam geçmişi modelleri, sosyal savunma kuramı

\begin{abstract}
The immense literature on attachment is dominated by an abundance of findings highlighting the benefits of secure attachment and the adverse outcomes associated with insecure attachment, yet nearly half of the population is consistently found to be insecurely attached. This poses an interesting conundrum, recently named as the attachment paradox. Two distinct but complementary evolutionary perspectives to attachment have put forward a solution to this paradox by proposing that different attachment tendencies offer distinct adaptive advantages contingent to different environmental conditions. The life history models of attachment argue that insecure attachment leads to increased reproductive fitness in harsh ecologies and the social defense theory complements this framework by positing that insecure attachment enhances chances of group survival under conditions of imminent threat. The aim of this article is to review these two perspectives investigating the conditions under which insecure attachment can be adaptive and the studies carried out within their framework, and present them to the Turkish literature.
\end{abstract}

Keywords: Attachment paradox, functions of attachment insecurity, life history models of attachment, social defense theory

Yazışma Adresi: Dr. Ezgi Sakman, Bilkent Üniversitesi, Psikoloji Bölümü, 06800 Bilkent / Ankara

E-posta: ezgi.sakman@bilkent.edu.tr

Gönderim Tarihi: 18.02.2017

Kabul Tarihi: 09.11.2017 
Hem korunmasız insan yavrusunun erken dönemde hayatta kalma problemi hem de yetişkin insanın ileri dönemde bağ kurma ve üreme problemi, büyüten ve yaşamsal destek veren kişilere (bağlanma figürleri) yakınlığ 1 sağlayan evrimsel kökenli bağlanma davranışsal sistemi ile çözülür (Bowlby, 1969/1982, 1973, 1980). Bu sistem, ilk olarak yeni doğanı fiziksel ve psikolojik tehditlerden korur, hayatta kalmasını ve böylece türün devamını sağlar. Bağlanma sistemi, bağlanma figürleriyle yașanan erken dönem deneyimlerden kaynaklanan bireysel farkl1lıkları da kapsar. Bağlanma figürü çocuğun ihtiyaç duyduğu duyarlı bakımı tutarlı bir şekilde sağlarsa, çocukta güven ve değerlilik duygusu, yani güvenli bağlanma gelişir. Güvenli bağlanma birincil strateji olarak da adlandırılır. Ancak, bağlanma figürü bir şekilde temel bağlanma ihtiyaçlarını karşılayamazsa, çocuk ihtiyaç duyduğu güven duygusunu hissedemez ve güvensiz bağlanma gelişir. Erken dönemde başlayan bu döngü benzer mekanizmalarla erişkinlikte de devam eder. Çocuğun içinde bulunduğu bakım ve çevre koşullarına göre kristalize olan ve bağlanma yönelimlerini oluşturan İçsel Çalışan Modeller kişinin kendi benliği ve diğer insanlar hakkındaki zihinsel temsillerini içerir ve erken dönem bağlanmasını ileriki yaşlara taşır (Bowlby, 1969/1982, 1973, 1980; ayrica bkz., Bretherton ve Munholland, 2008). Bakımın tutarlı ve hassas olduğu ortamlarda yetișen çocukların içsel çalışan modelleri kendilerinin değerli ve sevilmeye layık, diğer insanların ise güvenilir ve ihtiyaç halinde erişilebilir olduğu temsilini içerir ve güvenli bağlanmanın zeminini oluşturur. Bakımın tutarlı ve/veya gönüllü olarak sağlanamadığı ortamlarda büyüyen çocukların içsel çal1şan modelleri ise kendilerinin değersiz, diğer insanların ise güvenilmez olduğu algısı ile kurgulanır ve buna bağl1 olarak güvensiz gelişir. Bağlanma yönelimleri yine bu içsel çalışan modeller aracılığ

Bağlanma kuramına göre, güvensiz bağlanma, genel olarak ikincil strateji olarak adlandırılan iki ayrı mekanizma sonucu ortaya çıkan iki bağlanma boyutu ile tanımlanır. Erken dönemde bağlanma figürü tutarlı bir biçimde katı, reddedici ve bakım vermeye niyetsiz/ gönülsüz ise çocuk aktivasyonu engelleme stratejisi (deactivating strategy) geliştirir. Bu strateji sonucunda çocuk, ilgisiz bakım verenden asgari düzeyde yardım alarak hayatını sürdürmeyi ve yalnızca kendine güvenmeyi öğrenir ve nihayetinde çocukta bağlanma kaçınması gelişir. Bağlanma figürü tutarsız, yetersiz/dengesiz veya orantısız şekilde müdahaleci olduğunda ise çocuk yüksek aktivasyon stratejisi (hyperactivating strategy) geliştirir. Tutarsızlığı nedeniyle davranışları öngörülemeyen bağlanma figüründen daha çok kaynak sağlayabilme şansını arttırabilmek için yakınlık arama davranışlarını yoğunlaştırır. Bunun sonucu olarak da çocukta bağlanma kaygısı gelişir (Cassidy ve Kobak, 1988; ayrıca bkz.,
Mikulincer ve Shaver, 2007 ikinci bölüm). Çocuklukta görünen bu örüntü benzer dinamiklerle yetişkin yakın ilişkileri için de geçerlidir (Cassidy, 2000; Hazan ve Shaver, 1987).

Hem güvenli hem de güvensiz bağlanma, çocuğun içinde bulunduğu bakım ortamının özelliklerine göre şekillenen içsel çalışan modeller ile birlikte geliştiği ve bu ortamın gerekliliklerine uygun davranışsal sistemleri tutarlı olarak organize edebildiği için uyumsal stratejiler içerir ve bir anlamda organize davranışlar olarak tanımlanabilir. Duyarlı ve öngörülebilir bakımın olduğu ortamlarda bakım verene koşulsuz güvenip dayanmak uygunken; bakımın tutarsız ve bazen müdahaleci olduğu ortamlarda kaynak aktarımını maksimize etmek için yakınlık arama davranışını yoğunlaştırmak, bakım verenin tutarlı olarak isteksiz ve mesafeli olduğu durumlarda ise zaten gönülsüz olan bakım vereni tamamen kaybetmemek için yakın arayışından kaçınmanın yaşamsal değeri vardır. Diğer taraftan, ebeveynin aşırı derecede korkutu$\mathrm{cu} /$ soğuk olduğu veya çocuğu istismar ettiği durumlarda çocuk ebeveyne sağlıklı bir biçimde bağlanamaz ve içinde bulunduğu ortamla uyumlu davranışsal sistemleri organize edemez. Genel popülasyonda $\% 5$ - \% 10 oranında görülen ve psikopatoloji ile ilişkili olan bu bağlanma biçimine yönelim sorunlu ya da dezorganize bağlanma adı verilir (Main ve Solomon, 1986). Diğer bağlanma örüntülerden temel bir farkl1lık gösteren dezorganize bağlanmada işlevsel bir bağlanma stratejisi geliştirilemez ve bu bağlanma türü gelişimsel olarak ciddi risk içeren uyum sorunları ile yakından ilişkilidir.

Son otuz y1lda Bowlby'nin $(1969,1973)$ bağlanma kuramı kapsamında muazzam sayıda araştırma üretilmiş, bağlanma boyutları ya da stilleri, hemen hemen bütün psikolojik kavramlarla ilişkilendirilmiştir. $\mathrm{Bu}$ araştırma bulgularının ortak teması, güvenli bağlanmanın her koşulda "makbul" bağlanma stili olduğudur. Örneğin, araştırmalarda, güvenli bağlanan bireylerin daha yüksek yaşam kalitesi, mutluluk ve öz saygıya sahip oldukları, yakın ilișki başlatma ve sürdürmede ve stresle başa çıkmada daha başarılı oldukları, akademik ve mesleki hayatta daha yetkin oldukları, hatta daha sağlıklı ve uzun yaşadıkları gösterilmiştir. Bunun tersine, araştırma bulguları tutarlı olarak güvensiz bağlanmanın problemli yakın ilişkiler, stresle işlevsiz başa çıkma, hayattan doyumsuzluk ve mutsuzluk, başarısız duygu düzenleme, düşük özsaygı, düşük bilişsel, akademik ve mesleki performans, hatta kötü fiziksel ve psikolojik sağlık gibi olumsuz sonuçlarla ilişkili olduğunu göstermiştir (kapsamlı bir derleme için bkz., Mikulincer ve Shaver, 2007). Bütün bu araştırmalar göz önüne alındığında, güvensiz bağlanmanın bireylerin ilişki ve yaşam kalitelerini düşüren önemli bir risk faktörü olduğu anlaş1labilir (Mikulincer ve Shaver, 2008). 
Bütün bu olumsuz sonuçlarına karşın güvensiz bağlanma varlığını hala sürdürmekte ve oldukça da yaygın olarak görülmektedir. Çok sayıda ülkede yapılan araştırmalar, nüfusun neredeyse yarısının, tüm gelişim aşamaları, kültürler ve ölçme tekniklerinden bağımsız olarak, güvensiz bağlanmaya yatkın olduğunu göstermektedir (bkz., Hesse, 2008; van IJzendoorn ve Sagi-Schwartz, 2008; Schmitt, 2010). Örneğin, erken dönem bağlanmasını ölçen araştırmalar, güvensiz bağlanmanın Afrika'da \% 43 ila \% 33 (Ainsworth, 1967; True, Pisani ve Oumar, 2001), İsrail'de \% 48 (Sagi, van IJzendoorn, Aviezer, Donnell ve Mayseless, 1994), Japonya'da \% 39 (Durrett, Otaki ve Richards, 1984), Batı Avrupa'da \% 34 (van IJzendoorn ve Kroonenberg, 1988) ve Amerika'da \% 33 (van Uzendoorn, Goldberg, Kroonenberg ve Frenkel, 1992) oranında görüldüğünü ortaya koymuştur. Güvensiz bağlanmanın yetişkinlik dönemindeki yaygınlığı daha da fazladır, Schmitt ve arkadaşlarının (2004) 56 ülkede yetişkin bağlanmasını ölçen çalışması da güvensiz bağlanmanın Afrika'da \% 70, Doğu ve Güney/ Güneydoğu Asya' da \% 65, Avrupa ve Amerika'da \% 55 oranları dolaylarında görüldüğünü göstermiştir (bu çalışmadan elde edilen bulguların grafiksel dağılımı için bkz., Schmitt, 2010).

Bağlanma kuramı, evrimsel bakış açısını benimser ve savunmasız insan yavrusunun bağlanma davranıșsal sistemi aracılığı ile bakım veren yetişkinlere yakınlığı sağlayarak hayatta kalma şansını arttırdığını öne sürer. Biyolojik sistemlerle yakın ilişki içinde çalışan bağlanma sistemi tehdit altında aktif olur ve doğal seçilime karş1 bir kalkan vazifesi görür (bir derleme için bkz., Simpson ve Belsky, 2008). Bağlanma kuramının bu evrimsel çerçevesi düşünüldüğünde, güvensiz bağlanmanın insan türüne herhangi bir uyumlayıcı (adaptive) üstünlük sağlamadan bin yıllardır doğal seçilimle elenmemiş olmas1, üstelik neredeyse güvenli bağlanma kadar yaygın olabilmesi mümkün olmamalıdır. Ein-Dor, Mikulincer, Doron ve Shaver (2010) yakın zamanda bu ilginç ikileme dikkat çekmiş ve bunu bağlanma paradoksu olarak adlandırmıştır.

Bağlanma kuramı, orijinal haliyle, evrimsel bakış açısından bebeğin hayatta kalmasına odaklanır, ancak bağlanma kaygısının ve kaçınmasının neden evrimleşmiş olabileceğini odağına almaz. Buna ek olarak, yukarıda da tartışıldığı gibi, ana akım bağlanma araştırmaları temel olarak güvenli bağlanmanın faydalarına yoğunlaşmış ve güvensiz bağlanmanın olası işlevini son yıllara kadar göz ardı etmiştir. Ancak, doğrudan bağlanma paradoksuna değinmeden de olsa, bazı bağlanma araştırmacıları organize bağlanma kategorisi içindeki ikincil bağlanma stratejilerinin de içinde geliştikleri çevreye adaptasyon için işlevsel değeri olabileceğini öne sürmüştür (örn., Belsky, Steinberg ve Draper, 1991; Chis- holm, 1996; Hinde, 1982; Main, 1981, 1990). Tüm bu çalışmalarla geleneksel bağlanma araştırmalarının geçmişte yaptığı gibi sadece farklı bağlanma örüntülerinin nasıl geliştiğine değil, neden geliştiği sorusuna da cevap aranmaya başlanmıştır.

$\mathrm{Bu}$ derleme makalesinde önce güvensiz bağlanmanın üreme uygunluğunu arttırmak için evrimleşmiş olabileceğini öne süren bağlanmanın yaşam geçmişi modelleri (the life history models of attachment) ele alınacaktır. Ardından da bu evrimsel perspektifi tamamlamak için son y1llarda ortaya atılan ve güvensiz bağlanmanın grubun hayatta kalması için uyumlayıcı olabileceğini öne süren sosyal savunma kuramı (the social defense theory) ve bu kapsamda yapılan çalışmalar özetlenecektir.

\section{Güvensiz Bağlanmanın Üreme Bakımından Uyumlayıcı Değeri: Bağlanmanın Yaşam Geçmişi Modelleri}

Bağlanma yazınında güvenli bağlanmanın yakın ilişkiler kurmak için en optimal strateji olduğu görüşü bazı araştırmacılar tarafından eleştirilmiş ve ikincil bağlanma stratejilerinin uyumlayıcı değeri tartışılmıştır. İlk olarak Hinde (1982; Hinde ve Stevenson-Hinde, 1990), güvensiz bağlanma eğiliminin bazı özel ekolojik konum ve yaşam koşullarına uyumu kolaylaştırmak bakımından evrimsel avantajları olabileceği fikrini ortaya atmıştır. Benzer şekilde Lamb, Thompson, Gardner, Charnov ve Estes (1984) uyumu garantileyen tek bir evrimsel strateji olamayacağını belirtmiş ve güvenli bağlanmanın tek uyumlayıcı strateji olarak kavramsallaştırılmasını, evrimsel mekanizmaların ve doğal seçimin yanlış anlaşılması olarak yorumlamıştır. Main $(1981,1990)$ de bakım verenin duyarlı ve tutarlı bakım vermeye gönüllü olmadığı durumlarda, ikincil stratejilerin bakım vereni tamamen kaybetmemek ve onunla bir çeşit ilişki kurabilmek için işlevsel olarak geliştiğini iddia etmiştir. $\mathrm{Bu}$ ilk eleştiriler güvensiz bağlanmanın kimi koşullar altında uyumlayıcı fayda sunabileceği görüşünün sistematik olarak kuramsallaştırılmasına yol açmıştır.

Bağlanma sisteminin sadece erken dönemde yeni doğanın hayatta kalmasını sağlamak için değil, aynı zamanda yetişkinlikte üreme uygunluğunu arttırmak için çevreye duyarlı bir mekanizma olarak evrimleşmiş olabileceği görüşüne dayanan kuramsal yaklaşımlar (Belsky ve ark., 1991; Chisholm, 1996; ayrıca bkz., Ellis, 2004; Kirkpatrick, 1998; Zeifman ve Hazan, 1997), büyük ölçüde yaşam geçmişi kuramından etkilenmiştir (Charnov, 1993; Stearns, 1992). Yaşam geçmişi kuram1, büyüme, olgunlaşma, üreme, yaşlanma ve ölüm örüntülerinde gözlenen değişimlerin evrimsel yorumuna dayanır. Bu kurama göre, bütün organizmalar sınırlı kaynaklara sahip olduğundan, bu kaynakları hayatta kalma/ 
büyüme ve üreme şeklindeki iki temel hedef arasında paylaştırmak zorunda kalırlar. Bireyin yüzleştiği temel ikilemler, şimdi mi yoksa gelecekte mi üreyeceğine, döllerinin niteliğini mi niceliğini mi azami seviyeye çıkaracağına ve çiftleşmeye mi yoksa ebeveynlik yapmaya mı yatırım yapacağına karar vermektir. Kuram, kısıtlı kaynakların çevrenin koyduğu kısıtlılıkları da dikkate alarak bu rakip hedefler arasında optimum şekilde paylaştırılmasını sağlayan (ve böylece üreme uygunluğunu azami düzeye çıkaran) mekanizmaların doğal seçilimle hayatta kalacağını öngörür (bkz., Kaplan ve Gangestad, 2005).

Yaşam geçmişi kuramından yola çıkılarak, ebeveynlerin çocuklarına sundukları bakımın kalitesinin içinde bulunulan çevrenin özelliklerini çocuğa erken dönemde işaret ettiği iddia edilmiştir. Bu erken işaretçilerin, çocukların psikolojik, fiziksel ve üreme gelişimini, o çevreye uyumu azami düzeye çıkaracak şekilde bağlanma örüntüleri aracılığıyla biçimlendirdiği düşünülmüştür. Böylece, bağlanma güvenliğindeki bireysel farklılıklar (yani güvensiz bağlanma) bir anormallik olarak değil, üreme başarısını azami düzeye çıkarmak amacıyla çevreye uyum sağlamayı kolaylaştıran evrimleşmiş, uyumlayıcı stratejiler olarak değerlendirilir. Sonraki bölümde, bağlanmanın yaşam geçmişi modellerinden en önemli iki temsilcisi olan Belsky ve arkadaşlarının modeli (1991) ile Chisholm modeli (1996) ayrıntılı olarak ele alınacaktır.

\section{Belsky ve Arkadașlarının Modeli}

Belsky ve arkadaşları (1991), Draper ve Harpending (1982) tarafindan ortaya atılan babanın yokluğunun çocuğun gelecekteki üreme stratejisini şekillendirdiği fikrini geliştirmiş ve erken dönem aile deneyimlerinin bireyi yetişkinlikte farklı üreme stratejilerine nasıl sevk ettiğini açıklayan bir model öne sürmüşlerdir. Bu farklı üreme stratejilerinin, farklı gelişimsel örüntüler sonucu ortaya çıktığı ve üreme uygunluğunu ekolojik şartlara bağlı olarak arttırdığı düşünülmüștür. Model, sosyal ve ekolojik bağlamın (örn., çevresel stres, yetersiz kaynaklar, mutsuz evlilik) ebeveynliği etkilediğini (örn., bakım vermenin duyarlığı), bunun da çocuğun psikolojik ve davranışsal gelișimini (örn., bağlanma örüntüsü ve içsel çalıșan modeller) belirlediğini öne sürer (Belsky ve ark., 1991). Model çerçevesinde, çocuğun psikolojik ve davranışsal gelişiminin bedensel gelişimi (örn., cinsel olgunlaşma) etkilediği ve bunun üzerinden de yetişkinlikteki üreme stratejisini (örn., k1sa vadeli veya uzun vadeli çiftleşme, düşük veya yüksek kaliteli döl) şekillendirdiği öne sürülmüştür (Belsky ve ark., 1991). Belsky ve arkadaşları, erken dönem aile ortamında kaynakların kıt ve/ veya öngörülemez, insanların güvenilmez ve ilişkilerin istikrarsız olduğunu öğrenen çocukların güvensiz bağ- lanma geliştirdiğini, cinsel olgunluğa erken ulaştığını, erken başlayan, kısa vadeli ve çok eşli bir üreme stratejisi benimsediğini ve kendi çocuklarına da düşük ebeveynlik yatırımı sunduğunu iddia eder. Buna zıt olarak, modele göre, kaynakların devamlı erişilebilir olduğunu, insanların güvenilir ve ilişkilerin ödüllendirici olduğunu gösteren erken dönem deneyimleri yaşayan çocuklar güvenli bağlanma geliştirirler, cinsel olgunluğa geç ulaşırlar, geç başlayan, uzun vadeli ve tek eşli bir üreme stratejisi benimserler ve kendi çocuklarına da yüksek ebeveynlik yatırımı yaparlar.

Belsky ve arkadaşları (1991), her iki stratejiyi de çevre koşullarına karşı adaptasyonlar olarak geliştikleri için biyolojik açıdan geçerli olarak değerlendirmektedir. Güvensiz bağlanma ile tanımlanan kısa vadeli çiftleşme stratejisi, düşük ebeveyn yatırımı içerir. Bu strateji, kaynakların kıt ve öngörülemez olduğu istikrarsız ve zorlu çevrelerde döl niceliğini azami seviyeye çıkardı̆̆ 1 ve böylece (yeterince iyi bakılmasalar bile) yavruların en azından bir kısmının hayatta kalma olasılığını arttırdığı için daha uyumlayıcıdır. Savaş, kıtlık, büyük doğal felaketler ve kitlesel göç dönemlerinde nüfus artışının hızlanması buna bir örnektir. Diğer yandan, uzun vadeli çiftleşme stratejisi güvenli bağlanma ile tanımlanır ve yüksek ebeveyn yatırımı içerir. Bu strateji ise, kaynakların bol ve sürekli olduğu istikrarlı çevrelerde döl niteliğini azami seviyeye çıkardığı ve böylece bu yavruların ortamın kaynaklarını en iyi şekilde kullanarak ideal şekilde gelişmesini sağladığı için daha uyumlayıcıdır. Yüksek sosyoekonomik konumdaki ailelerin az sayıda çocuk sahibi olarak bu çocukların en iyi şekilde yetişmelerini hedeflemeleri buna bir örnektir. Her iki strateji de türün kendi ekolojisi içinde uzun vadede hayatta kalma şansını arttırır. Bu yüzden, farklı bağlanma örüntülerinin farklı çevresel şartlara uygun çiftleşme stratejilerini destekleyerek üreme uygunluğunu arttırdığ 1 için evrimleşmiş olabileceği iddia edilmiştir (Belsky, 1999).

Belsky (1997), daha sonra bu modeli farklı güvensiz bağlanma stillerini de açıklayacak șekilde geliştirmiştir. Orijinal modelde bahsedilen güvensiz bağlanmanın çoğunlukla kayıtsız/kaçınan bağlanmaya karşılık geldiğini açıklamış ve bağlanma kaçınmasının ailelerin daha yüksek stres altında olduğu ve daha az/ öngörülemez kaynaklara sahip olduğu kültürlerde daha yaygın olarak görüleceğini tahmin etmiştir. Ayrıca Belsky, bağlanma kaygısının, kişiyi ebeveynler ve diğer aile üyeleri ile birlikte evde kalarak onların üreme başarısına ulaşmalarına yardım edecek yuvadaki-yardımcı (helperat-the-nest) davranışlarına sevk eden ve bu davranışlar aracılığıyla üreme uygunluğunu dolaylı yoldan arttıran bir mekanizma olarak evrimleşmiş olabileceğini de iddia etmiştir. Ancak, bu düşünce görgül destek bulamamıştır (bkz., Simpson ve Belsky, 2008). 


\section{Chisholm Modeli}

Belsky ve arkadaşlarının (1991) modeli döllerin niceliği ve niteliği arasındaki ikilemi vurgularken, Chisholm'ün $(1993,1996)$ genişletilmiş modeli, şimdiki zamanda (anında) ve gelecekte (ertelenmiş) üreme arasındaki ikileme odaklanmıştır. Chisholm, uzun vadeli ve kısa vadeli çiftleşme stratejisi arasındaki seçimin en önemli belirleyicilerinden birinin yerel ölüm oranlar olduğunu iddia eder. Chisholm'ün kuramına göre, ölüm oranları yüksek olduğunda, ideal üreme stratejisi erken yaşta ölmeden önce en azından bir kaç yavru üretecek şekilde erken çiftleşmektir. Diğer yandan, düşük ölüm oranlarının olduğu bir çevrede ertelenmiş üreme optimal strateji olarak benimsenebilir. Bu uzun vadeli üreme stratejisi ile her bir kuşak içinde hayatta kalan döl sayısındaki fark asgari seviyede tutularak kuşaklar boyunca hayatta kalan toplam soy üyesi sayısı azami seviyeye taşınabilir.

Chisholm $(1993,1996)$ ölüm oranlarının, üreme stratejilerini yönlendirmenin yanı sıra, yerel çevrenin zorluğunun bir göstergesi olarak da görev yaptığını öne sürer. Chisholm'e göre, ölüm oranları çocuklara aldıkları ebeveyn yatırımı seviyesi aracılı̆̆ıyla "uyumlayıcı" bağlanma stilleri geliştirmeleri için işaretler verir. Modele göre, yoksulluk, açlık, hastalıklar, savaş, vb. yüksek ölüm oranları ile ilişkili göstergeler, ebeveynler için yüksek stresi yordar ve duyarsız ebeveynliğe neden olur. Duyarsız ebeveynliğin sonucu olarak da çocukta güvensiz bağlanma gelişir. Chisholm ayrıca iki tip güvensiz bağlanmayı birbirinden ayırt eder ve bağlanma kaçınmasının ebeveynin yatırım yapmaya istekli olmamasina, bağlanma kaygısının ise ebeveynin yatırım yapmaya istekli ancak ebeveynlik bakımindan yetkin olmamasina karşı birer uyumlayıcı strateji olarak evrimleşmiş olabileceğini öne sürer. Modele göre, çocuğa yatırım yapmaya istekli olmamak, ebeveynin zorlu yerel ekoloji nedeniyle benimsediği ve kaynakların daha yüksek hayatta kalma şansı olan diğer döllere veya yeni döller yaratmaya ayırdığı optimal üreme stratejisinin bir sonucudur. $\mathrm{Bu}$ da duyarsız ve reddedici bakım verme olasılığını artırarak çocukta bağlanma kaçınması gelişmesine yol açar. Diğer yandan, çocuğa yatırım yapma konusunda yetkin hissetmeyen ebeveynlerin yüksek bağlanma kaygısının yetersiz veya öngörülemez kaynakların bir sonucu olduğu öne sürülmektedir. $\mathrm{Bu}$ da dengesiz ve tutarsız bakım vermeye yol açtı̆̆ından çocukta bağlanma kaygısı gelişir. Bu ebeveynler reddedici veya duygusal olarak uzak değildir ama ihtiyaç duydukları kaynaklara sahip olmadıkları için duyarlı ve tutarlı bakım veremezler. Yine modele göre, düşük ölüm oranlarının olduğu elverişli ekolojilerde ise ebeveynler çocuklarına yatırım yapmaya hem istekli hem de yetkin olabilirler ve böylece onlara hassas ve duyarlı bakım verebilirler. Bu da çocukta güvenli bağlanmanın gelişmesini sağlar.
Düşük ölüm oranlarının olduğu ekolojilerde güvenli bağlanan çocuklar yüksek ebeveyn yatırımının tadını daha uzun süre çıkarabilirler. Böylece kendi kaynaklarını gelişmeye ayırarak üremeyi erteleyebilirler. Buna uygun olarak uzun vadeli eş ararlar ve kendi çocuklarına da yüksek ebeveyn yatırımı sunarlar (Chisholm, 1996). Bunun aksine, zorlu çevre koşulları altında bağlanma kaçınması geliştiren çocuklar reddedici aileleri tarafından erken yașta bağımsız olmaya zorlandıkları için kısıtlı kaynaklarını erken yaşta üremeye ayırıllar ve kısa vadeli üreme stratejisi benimserler. Chisholm, bağlanma kayg1s1 yüksek çocukların ise tutarsız ebeveynlerinden kaynak isteme girişimlerini bırakamadıklarını, ancak aldıkları kaynakları (örneğin sosyal destek) kendi gelişimlerinden ziyade erken yaşta üremeye yönlendirdiklerini öne sürer. Bu bakış açısı içinde de güvenli bağlanma tek işlevsel bağlanma yönelimi olarak görülmez. Tam tersine, farklı bağlanma yönelimlerinin gelişimi daha yüksek üreme uygunluğu olarak ortaya çıkan bir yerel ortam adaptasyonu olarak değerlendirilir (Chisholm, 1993, 1996).

Yukarıda incelenen bağlanmanın yaşam geçmişi modelleri geniş çaplı görgül destek bulmuştur (derlemeler için bkz., James ve Ellis, 2013; Simpson ve Belsky, 2008). Geçmiş çalışmalarda zorlu çevresel koşullar (örn., patojenler, yüksek ölüm oranları, ekonomik güçlükler, belirsizlik, psikolojik stres) ile reddedici ve duyarsız ebeveynlik (bir derleme için bkz., Hoff, Laursen ve Tardif, 2002) ve yüksek düzeyde bağlanma kaçınması ve kaygısı (Solak, Sakman, Sümer ve Schmitt, 2017) arasındaki ilişkiler gösterilmiştir. Ayrıca güvensiz bağlanma ile kısa vadeli üreme stratejisi arasındaki ilişki de ortaya konmuştur (örn., Gangestad ve Buss, 1993; Griskevicius, Delton, Robertson ve Tybur, 2011; Koehler ve Chisholm, 2007, 2009; Schmitt, 2008). Duyarsiz ebeveynlik ile güvensiz bağlanma ve kısa vadeli üreme stratejisi arasındaki ilişkiler de bilinmektedir (bkz., Mikuliner ve Shaver, 2007). Buna ek olarak boylamsal veriler erken başlayan ve riskli cinsel davranışın yaşam geçmişi kuramı tarafindan ortaya atılan birbiriyle ilişkili mekanizmalardan etkilendiğine dair kanıt sunmuştur. Zorlayıcı çevre ve yüksek belirsizlik anne duyarlılığını olumsuz etkilemekte, sert ebeveynlik pratikleri ve düşük kaliteli aile ilişkileri ise erken buluğa ermeyi yordamaktadır. Bu faktörlerin hepsi bir arada ergenlikte cinsel risk alma davranışını artırmaktadır (Belsky, Schlomer ve Ellis, 2012; Belsky, Steinberg, Houts, Halpern-Felsher ve the NICHD Early Child Care Research Network, 2010; James, Ellis, Schlomer ve Garber, 2012; Zimmer-Gembeck ve Helfand, 2008).

Bağlanmanın yaşam geçmişi modelleri bağlanma yazını içinde önemli bir yere sahiptir. Bu modeller bütün bağlanma yönelimlerinin optimal uyumu sağlamak için çevresel koşullara göre evrilmiş adaptasyonlar olduğu- 
nu, hiç birinin diğerinden "iyi” olmadığını, ancak bazılarının belli ortamlarda diğerlerine göre daha işlevsel olduğunu öne sürmüştür. Böylece, bir anlamda güvenli bağlanmanın tek avantajlı bağlanma stili olduğu yönündeki ana akım düşünceye meydan okumuştur. Bu modellerin, bağlanma yönelimlerine uyumlayıcı bir açıklama getirmeleri bağlanma yazını için çığır açıcı bir katkıdır. Bununla beraber, sadece üreme uygunluğu noktasına odaklandıklarından güvensiz bağlanmanın özellikle sosyal ilişkilerde ve grup düzeyinde işlevselliği konusunda araştırmalara gereksinim vardır. Şayet farklı bağlanma yönelimleri gerçekten üreme uygunluğunu arttırmak için çevre koşullarına uygun adaptasyonlar olarak evrimleştiyse, üremenin ön koşulu hayatta kalmak olduğundan, bunlar aynı zamanda hayatta kalma konusunda da avantajlar sunmalıdır (Ein-Dor ve ark., 2010). Gerçekten de, Bowbly'nin (1969/1982) bağlanma sistemi kavramsallaştırmasında korku sistemi hayatta kalma ile yakından bağlantılıdır. Bağlanma sistemi hayatta kalmayı garantilemek için çevresel tehdit işaretleri ile aktive olur. $\mathrm{Bu}$ nedenle, üreme uygunluğunu arttırmaya ek olarak farklı bağlanma yönelimlerinin aslında farklı çevresel koşullar altında hayatta kalma uygunluğunu arttırmak için uyumlayıcı faydalar sunduğu öne sürülebilir. Ayrıca, güvensiz bağlanma üreme stratejilerini yerel ekolojilere göre ayarlayarak üreme uygunluğunu arttırsa bile, bağlanma kaçınması ve kaygısı yüksek kişiler girişte tartışılan olumsuz sonuçlar ile karşı karşıya kalmaya devam etmektedir. Sonuç olarak, güvensiz bağlanma üremede evrimsel uyum sunarak işlevsel olsa bile birey düzeyinde belli oranlarda işlevsiz olduğu söylenebilir. Bu yüzden, güvensiz bağlanmanın uyumlayıcı faydasının birey düzeyinden başka bir analiz düzeyinde var olabileceği iddia edilebilir. Bağlanma paradoksunun çözümündeki bu boşlukları doldurmak için, Ein-Dor ve arkadaşları (2010), bağlanmanın yaşam geçmişi modellerine hayatta kalma alanında uyumlayıcı fayda ve grup düzeyinde uyumlayıcı fayda kavramlarını ekleyerek, bu modelleri tamamlayacak olan sosyal savunma kuramını ortaya atmıştır.

\section{Güvensiz Bağlanmanın Grup Düzeyinde Hayatta Kalma Bakımından Uyumlayıcı Değeri: Sosyal Savunma Kuramı}

Ein-Dor ve arkadaşları (2010), ortaya koydukları sosyal savunma kuramında hem güvenli hem de güvensiz bağlanma yönelimlerinin belirli koşullar altında uyumlay1c1 faydası olabileceğini öne sürmüştür. Bu yüzden de farklı bağlanma yönelimlerine sahip kişilerden oluşan grupların, bağlanma yönelimi bakımından homojen yapıda olan gruplara göre daha yüksek hayatta kalma şans1 olduğu iddia etmişlerdir. Yukarıda sunulduğu gibi, bağ- lanma yazınında güvenli bağlanmanın avantajları kapsamlı olarak ortaya konulmuşken güvensiz bağlanmanın olası uyumlayıcı faydalarına dair pek fazla bulgu yoktur. $\mathrm{Bu}$ nedenle, ana akım bağlanma araştırmaları paradigmasına eleştiri olarak Ein-Dor ve arkadaşları, güvensiz bağlanmanın evrimsel uyumlayıcı faydasının birey düzeyinde değil grup düzeyinde olabileceği ve bu sayede doğal seçilimden başarıyla çıkmış olabileceği fikrini öne sürmüştür. Ein-Dor ve arkadaşlarının savları, bir kișinin kapsaml seçilim değerinin (total/inclusive fitness) sadece kendi üreme başarısıyla değil akrabalarının üreme başarısıyla da belirlendiğini savunan Hamilton'ın (1964) akraba seçimi kuramına ve Sober ve Wilson'ın (1998) çok düzeyli seçilim kuramına (multilevel selection theory) dayanmaktadır. Bu kuramlara göre, birey düzeyinde işlevsiz gibi görünen ama gruba fayda sağlayan pek çok sosyal özellik (örn., özgecilik) grup seçilimi süreçlerinde grubun hayatta kalma olasılığını arttırdığından evrimsel olarak uyumlayıcıdır ve doğal seçilimle elenmez. EinDor ve arkadaşları, bu kuramlara dayanarak güvensiz bağlanmanın birey düzeyinde işlevsiz olsa bile grup düzeyinde uyumlayıcı olduğundan hala hayatta kaldığını iddia eder.

Güvenli bağlanan grup üyeleri grup faaliyetlerinin eşgüdümünü sağlamakta daha başarılıdır ve normal koşullarda grup üyelerinin etkinliğini artırır (Rom ve Mikulincer, 2003). Sosyal savunma kuramına göre, güvensiz bağlanmanın görece uyumlayıcı faydası ise tehdit durumlarında ortaya çıkar (Ein-Dor ve ark., 2010). Güvenli bağlanan bireylerin sahip olduğu içselleştirilmiş güvenlik ve rahatlık hissi normal koşullarda kendileri için yararlı olsa bile, çevrede bir tehlike baş gösterdiğinde dezavantajlarına olabilir. Güvenli bağlanan bireylerin tehdit işaretlerine karşı pek uyanık olmaması ve tehdit algılandığında da otomatik olarak bağlanma figürlerine yönelmeleri (örn., Mikulincer, Gillath ve Shaver, 2002), acil bir durum erken tespit ve hızlı kaçış gerektirdiğinde aleyhlerine işleyebilir. Görece koşulsuz güven hisleri erken tehdit işaretlerini tespit etmelerini erteleyebilir ve bağlanma figürlerine yakın olma yatkınlıkları kendilerini kurtarmak için küçük kaçış şanslarını kaçırmalarına sebep olabilir. Yangın, terör saldırıları, patlamalar, vb. felaketler sırasındaki davranışları inceleyen çalışmalar tanıdıkları ile yakın mesafede olan insanların tehdidin erken ve muğlak belirtilerini algılama olasılıklarının daha düşük olduğunu, ancak tehdit bariz bir hale geldiğinde tepki verdiklerini, herkes bir araya gelmeden tahliye etmeyi reddettiklerini ve grup halinde hareket etme eğiliminde olduğunu göstermektedir (örn., Aguirre, Wenger ve Vigo, 1998; Proulx, 2003; Sime, 1983). Bu davranış örüntüsü, tahliye sürecini uzattığı için hem tek tek bireyler hem de grubun tamamı için ölüm riskini arttırır (Feinberg ve Johnson, 2001). Tüm bunlar sadece güvenli 
bağlanan bireylerden oluşan bir grubun acil bir durumda tehdit işaretlerine karşı kolektif yavaş tepki vermesinden ve herkes bir araya gelmeden kaçmayı reddetmesinden dolayı dezavantajlı konumda kalabileceğini ve hayatta kalma olasılıklarının azalabileceğini akla getirmektedir (Ein-Dor ve ark., 2010).

Sosyal savunma kuramı güvenli bağlananların tersine, güvensiz bağlanan bireylerin, tehdide karşı içselleştirilmiş tepkilerinden dolayı bu gibi tehlikeli durumlarda avantajlı olabileceği fikrini ortaya atmaktadır (Ein-Dor ve ark., 2010). Bağlanma kaygısı yüksek olan bireyler, bağlanma sistemleri kronik olarak yüksek aktivasyon düzeyinde olduğundan tehdit ve stres işaretlerine karşı hep tetiktedir: Fiziksel veya sosyal tehdit ipuçlarını daha kolay ve hizlı tespit ederler ve bunlara daha yoğun tepki verirler (Ein-Dor ve Perry, 2014; Mikulincer, Birnbaum, Woddis ve Nachmias, 2000; Mikulincer ve ark., 2002). Sosyal savunma kuramı, bağlanma kaygısı yüksek bireylerin bu şema ve eylem yatkınlıklarından dolayı grup için iyi birer bekçi (sentinel) olabileceğini iddia eder. Bu bekçiler, ortaya çıkmakta olan bir tehlikenin erken ve muğlak işaretlerini (örn., alışık olunmayan ses, çatırt1, koku ve hareketler) zamanında tespit eder ve grubun diğer üyelerini uyarırlar. Böylece, grubun güvenli bağlanan üyelerinin tehdit işaretlerini tespit etmedeki eksiklerini kapatıp, grup düzeyinde hayatta kalmak için uyumlayıcı fayda sunabilirler.

Diğer yandan, bağlanma kaçınması yüksek olan bireyler temel olarak sadece kendine güvenen ve kendini koruyan faydacı bir yapıya sahiptir ve kronik olarak kaçmaya eğilimlidir (örn., Mikulincer ve Shaver, 2007). Sosyal savunma kuramı, yüksek bağlanma kaçınması olan kişilerin bu özelliklerinin onları tehlike anlarında hızlı savaş-veya-kaç (rapid fight-or-flight) tepkileri vererek kimseden yardım beklemeden kendilerini korumaya ve (her zaman olumsuz durumdan kaçmaya meyilli oldukları için) kaçış yollarını daha çabuk fark etmeye yatkın hale getirdiğini iddia eder (Ein-Dor ve ark., 2010). Diğer kişilerin, grubun bağlanma kaçınması yüksek üyelerinin fark ettikleri veya yarattığı bu kaçış yollarını onları takip ederek kullanma olasılığı yüksektir. Bu mekanizma nedeniyle bu eylem yatkınlıklarının grubun geri kalanı için de faydalı olduğuna işaret edilmiştir. Böylece, Ein-Dor ve arkadaşlarına göre bağlanma kaçınması yüksek olan grup üyeleri, tahliye stratejileri aramaktansa bağlanma figürlerini bulmak ile meşgul olan grubun güvenli bağlanan diğer üyeleri için de bir kurtuluş seçeneği yaratarak grup düzeyinde uyumlayıcı fayda sağlamış olurlar.

Sosyal savunma kuramı, bağlanma yönelimi güvensiz olan bireylerin tehlike anındaki bu şema ve eylem yatkınlıklarını düşünerek, üyelerinin bağlanma yönelimleri bakımından heterojen olan (yani hem güvenli, hem bağlanma kaygısı yüksek, hem de bağlanma kaçınması yüksek üyeleri olan) grupların, sadece güvenli bağlanan üyeleri olan homojen gruplara kiyasla daha yüksek hayatta kalma şansı olacağı fikrini öne sürmüştür (Ein-Dor ve ark., 2010). Kuram, güvensiz bağlanmanın birey düzeyindeki işlevsizliğine rağmen doğal seçilim baskısına dayanabilmesinin sebebinin işte bu grup düzeyindeki evrimsel uyumlayıcı fayda olduğunu kabul eder.

Sosyal savunma kuramı biliş ve davranış seviyelerinde görgül olarak da incelemiştir. Ein-Dor, Mikulincer ve Shaver (2011a), bir seri çalışma dahilinde bekçi ve hızlı savaş-veya-kaç şemalarının bilişsel erişilebilirliğini bağlanma yatkınlıları temelinde araştırmışlardır. Bu çalışmada bağlanma kaygısı yüksek olan katılımcıların farazi bir tehlike hikayesinde bekçi senaryosuyla (örn., tehdidin muğlak işaretlerini diğerlerinden önce fark etmek, diğerlerini tehlike konusunda uyarmak) daha uyumlu öyküler yazdıkları, bu senaryoyla uyumlu bilgileri daha hızlı, detaylı ve şema-yanlı bir şekilde işlemledikleri ve yine bu senaryoyla uyumlu bellek yanlılıkları gösterdikleri bulunmuştur. Diğer taraftan bağlanma kaçınması yüksek olan katılımcılar hızlı savaş-veya-kaç senaryosunu (örn., başkalarının hareketini ve yardımını beklemeden hızlıca tepki verme) çağrıştıran öyküler yazma, bu senaryoyla uyumlu bilgileri daha hızlı tanıma, daha derin işleme ve bu senaryolarla ilgili şema-uyumlu bilgileri daha çok hatırlama eğilimleri göstermişlerdir. Yeni bir çalışmada, Ein-Dor ve Perry-Paldi (2014) katılımcılarından farazi tehlike senaryolarında gösterecekleri en muhtemel ilk tepkilerini seçmelerini istemiştir. Yüksek bağlanma kaygısı olan katılımcılar çı̆̆lık atmayı ve çı̆̆lık atmakla tehdit etmeyi (bekçi tepkisi) tehdide karşı daha muhtemel bir tepki olarak belirtirken, yüksek bağlanma kaçınması olanlar saldıracaklarını veya saldırmakla tehdit edeceklerini (savaş tepkisi) veya kaçacaklarını (kaç tepkisi) daha çok ifade etmişlerdir. Yüksek bağlanma kaygısı olan insanların potansiyel tehditleri gözlemek ve tespit etmek konusunda kolay erişilebilir ve iyi organize edilmiş zihinsel şemaları olduğu ve bu tehditlere karşı seslerini yükselterek tepki verdikleri anlaşılmaktadır. Yüksek bağlanma kaçınması olanların ise uzun uzadıya düşünmeden kendilerini nasıl hızlıca koruyacaklarına dair aktif zihinsel şemaları olduğu görülmektedir. Tüm bu bulgular güvensiz bağlananların bekçi ve hızlı savaş-veya-kaç tepkilerine bilişsel düzeyde yatkınlıkları olduğuna dair görgül kanıt sunmaktadır.

Ein-Dor, Mikulincer ve Shaver (2011b), kuramlarının öngörülerini davranış düzeyinde de incelemişlerdir. $\mathrm{Bu}$ çalışmada katılımcılar laboratuara üç kişilik gruplar halinde alınmış ve içeride gerçekte var olmayan ama katılımcıların gerçek olduğunu sandıkları sözde bir tehlike durumu yaratılmıştır. Çalışmanın sonuçları yüksek bağlanma kaygısı olan katılımcıların bu tehlikeyi ilk fark eden kişi olma, yüksek bağlanma kaçınması olan katılım- 
c1ların ise bu tehlikeden ilk kaçan kişi olma olasılıklarının anlamlı seviyede yüksek olduğunu göstermiştir. Üstelik bu çalışma bağlanma yönelimlerine göre heterojen olan grupların bu tehdidi fark etme ve onunla baş etme konusunda hem daha hızlı hem de daha etkili olduğunu göstermiştir. Bu bulgular, bekçi ve hızlı savaş-veya-kaç tepkilerinin aynı zamanda davranışsal düzeyde işlediğini ve güvensiz bağlanan insanların tehdit durumlarına nasıl tepki vereceğini etkilediğini göstermiştir. Bu çalıșmayla ayrıca, bağlanma bakımından heterojen olan grupların, tehdit işaretlerine karşı dikkatli ve tehlikeye karşı hızlı tepki verebilen üyeleri sayesinde tehdit durumlarında daha avantajlı konumda olabileceğine ilişkin bulgular da elde edilmiştir.

\section{Tartışma}

Güvensiz bağlanma, her ne kadar birey için başar1sız duygu düzenleme, problemli yakın ilişkiler ve düşük hayat doyumu gibi pek çok olumsuz sonuçlar doğursa ve yaşam/ilişki kalitesi için bir risk faktörü oluştursa da (bkz., Mikulincer ve Shaver, 2007, 2008), hala \% 40 civarında bir oranla bütün kültürlerde görülmektedir (bkz., Hesse, 2008; van IJzendoorn ve Sagi-Schwartz, 2008; Schmitt, 2010). Yarattı̆̆ bu olumsuz sonuçlar nedeniyle güvenli bağlanma gibi evrensel norm olmaması mantıklıdır, ancak varlığını hala bu yaygınlıkta sürdürebilmesi de çevre şartlarına adaptasyon gibi kimi uyumsal işlevleri yerine getirdiğine işaret etmektedir.

Bağlanma yazınının etkileyici genişliğine ve derinliğine karşın güvensiz bağlanmanın bu olası uyumlayıcı işlevleri yaygın olarak göz ardı edilmiştir. Halbuki, bu işlevleri araştırmak ve anlamak, güvensiz bağlanmanın yaygınlığının Amerikan örneklemlerinde son zamanlarda arttığını gösteren yeni bulgular 1şı ğında giderek daha çok önem kazanmaktadır (Konrath, Chopik, Hsing ve O’Brien, 2014). Güvensiz bağlanma ile ilişkili olduğu bilinen narsisizm (Twenge, Konrath, Foster, Campbell ve Bushman, 2008), bireycilik (Twenge, 2006) ve eylem odaklılık (Twenge, 1997) özelliklerindeki artış ve empati düzeylerindeki düşüş (Konrath, O’Brien ve Hsing, 2011) bu bulguyu açıklayabilir. İş-özel hayat dengesinin özel hayat aleyhine bozulması (örn., Fox, Han, Ruhm ve Waldfogel, 2012), geniş aile yapısından çekirdek ailelere geçiş ve artan boşanma oranları gibi değişen aile dinamikleri de güvensiz bağlanmanın artışında rol oynuyor olabilir. Gençleri bireyciliğe yönelten akıllı cihaz, video oyunu, internet gibi teknolojik gelişmeler (Konrath, 2012) de yine güvensiz bağlanmayı etkileyen faktörlerden olabilir. Kaynakların azaldığı, sosyo-politik değişimlerin aşırı bireyselleşme, narsisizm ve empati yoksunluğunu körüklediği diğer coğrafyalarda da güvensiz bağlanma eğilimlerinde benzer artışlar beklenebilir.
Güvensiz bağlanmanın bu konumundan yola çıkarak, bu derleme makalesinde güvensiz bağlanmanın üreme uygunluğunu ve grubun hayatta kalma olasılığını arttırdığ1 için uyumlayıcı olabileceğini savunan evrimsel bakış açısına dayalı iki kuram değerlendirilmiştir.

Ein-Dor ve arkadaşlarının (2010) grubun hayatta kalması temelindeki yaklaşımı ve Belsky ve arkadaşlarının (1991) ve Chisholm'ün $(1993,1996)$ üreme uygunluğu perspektifi birbirini tamamlamakta ve birey düzeyindeki çok sayıdaki olumsuz sonuçla ilişskisine karşın güvensiz bağlanmanın doğal seçilim baskısına yıllardır nasıl ve neden dayanabildiğini açığa kavuşturmaktadır. Güvensiz bağlanma sert ekolojilerde ve aniden ortaya çıkan tehdit durumlarında bireyi çevrenin taleplerine uygun uyumlayıcı üreme stratejilerine ve hayatta kalma taktiklerine yönlendirerek bir zırh vazifesi yapar. Böylece hem birey hem de grup düzeyinde başarıyla üreme ve hayatta kalma şansını arttırır. Aynı zamanda güvensiz bağlanma, yerel çevredeki zorlukların sinyalini veren ve insanlara bu koşullarda hayatta kalmalarını ve üremelerini sağlayacak gerekli adaptasyonları geliştirmelerine yardım eden bir nevi erken uyarı ve uzaklaşma sistemi olarak işlev görür. Hayatta kalmanın başarılı üreme için bir ön koşul olduğu ve grupların tek tek üyelerinin hayatta kalması için kritik olduğu (Baumeister ve Leary, 1995; Brewer ve Caporael, 2006; Caporael, 1997) düşünüldüğünde, Ein-Dor ve arkadaşlarının (2010) grubun hayatta kalması perspektifi tamamlayıcı bir bakış açısı olarak özellikle değer kazanmaktadır.

Güvensiz bağlanmanın grup düzeyindeki uyumlayıcı faydası tehlike durumunda hayatta kalmanın ötesine de geçebilir. Örneğin, güvensiz bağlanan bireyler gruplar arası duyguları (Smith, 1993) güvenli bağlanan diğer grup üyelerinden daha farklı algılayabilirler ve böylece gruba uyumlayıcı üstünlükler sunabilirler. Bağlanma kaçınması yüksek grup üyeleri, nefret, öfke ve tiksinme gibi güçlü duyguları hissetmeye daha yatkın olabilir. Bağlanma kaygısı yüksek grup üyelerinin ise utanç, üzüntü ve korku hissetme olasılığı daha yüksek olabilir. Duygusallıktaki bu fark, dış gruplarla ilişskileri dengeleyerek ve grup içinde bir denetleme işlevi görerek grubun tamamının yararına olabilir (Maitner, Mackie ve Smith, 2006). Bunun ötesinde, bağlanma bakımından heterojen yapıdaki gruplar, birbirini tamamlayan bağlanma yönelimleriyle iş ortamında daha işlevsel olabilir. Bağlanma kaygısı yüksek üyeler potansiyel problem ve tehditleri tespit etmede faydalı olabilir, bağlanma kaçınması yüksek üyeler çok fazla düşünmeden ve taviz vermeden hareket etmeyi kolaylaştırabilir, güvenli bağlanan üyeler ise lider ve koordinatör işlevlerini görebilirler. Lavy, Bareli ve Ein-Dor (2015) yakın zamanda bu görüşü destekleyen bulgular sunmuştur: Üyelerinin bağlanma yönelimleri bakımından heterojen olan öğrenci proje 
takımları, hem nesnel çıktılarda, hem de takım üyelerinin takımın performansıyla ilgili öznel algılarında daha başarılı bulunmuşlardır. Grup oluşturma süreçleri üzerindeki olas1 etkileri düşünüldüğünde, güvensiz bağlanmanın iş takımlarındaki uyumlayıcı üstünlükleri gelecek araştırmalar için verimli bir alan olabilir.

Güvensiz bağlanmanın işlevselliği çalışmaları grup analiz düzeyinden kültürel analiz düzeyine de taşınabilir. Bağlanma kuramının temel ilkeleri evrensel geçerliliğe sahip olsa da (van IJzendoorn ve Sagi-Schwartz, 2008), bağlanma davranışının nasıl şekillendiği kültürler arası farklılıklar göstermektedir. Toplulukçu kültürlerde bağlanma kaygısı daha yaygınken, yüksek bağlanma kaçınmasına bireyci kültürlerde daha çok rastlanmaktadir (bkz., Schmitt, 2010). Yakın zamanda ortaya atılan "kültüre uyum hipotezi"ne (the culture-fit hypothesis) göre, kültürde daha sık görülen güvensiz bağlanma biçimi daha az olumsuz sonuçlar doğurmaktadır (Friedman ve ark., 2010). Bağlanma kuramının normatiflik hipotezi (the normativity hypothesis) ile uyumlu olarak, farklı kültürel bağlamlar farklı güvensiz bağlanma stillerini (muhtemelen farklı güvensiz bağlanma biçimleri farklı kültürel talepleri daha iyi karşıladığı için) besliyor olabilir (Friedman ve ark., 2010; Sümer ve Kağıtçıbaşı, 2010). Güvensiz bağlanmanın farklı biçimlerinin farklı kültürel ortamlardaki uyumlayıcı değeri, bireycilik-toplulukçuluk, güç mesafesi, dişilik-erkeksilik, uzun vadeli-kısa vadeli oryantasyon ve belirsizlikten kaçınma gibi farklı kültürel değer boyutları (Hofstede, 2001) ile ilişkileri ve bu biçimlerin farklı kültürler tarafindan neden ve nasıl idame ettirildiği gelecek araştırmalar için değerli sorular olabilir. Güvenli bağlanma düzeyinde kültürler arası büyük farklılık yokken güvensiz bağlanma düzeyinde kültürel farklılıkların yaygın olması da (van IJzendoorn ve Sagi-Schwartz, 2008; Schmitt, 2010) öne sürülen uyumlayıcı ve işlevselci bakış açısıyla yorumlanabilir. Bununla tutarlı olarak Türkiye'de yapılan çalışmalar da kültürle uyumsuz olan bağlanma kaçınmasının bağlanma kaygısına görece daha yüksek risk taşıdığını göstermiştir. Bu çalışmalar, bağlanma kaçınmasının anne duyarlığı (Selcuk ve ark., 2010), ebeveynlere güvenli bağlanma (Sümer ve Kağıtçıbaşı, 2010), evlilik doyumu (Harma ve Sümer, 2016) ve orta çocuklukta arkadaşlık kalitesi (Sümer, 2015) gibi pek çok kritik değişkeni negatif yordadığını ortaya koymuştur.

Güvensiz bağlanmanın farklı biçimlerinin farklı kültürel ortamlarda, kültürdeki yaygın güvensiz bağlanma biçimine bağlı olarak, farklı uyumlayıcı değeri olabileceği fikri Sakman (2016) tarafindan sosyal savunma kuramına kültürel bağlamın eklendiği bir modelle öne sürülmüş ve deneysel olarak test edilmiştir. Çalışmanın sonuçları, kültürdeki yaygın güvensiz bağlanma eğiliminin daha fazla uyumlayıcı değerinin olacağı hipotezini desteklemiş ve güvensiz bağlanma davranışlarının, kültürdeki yaygın bağlanma boyutu-kültürel değer ilişkisi ile uyumlu olduğu sürece kültürün üyeleri tarafından işlevsel algılandığını göstermiştir. Bu sonuçlar, güvensiz bağlanmanın erken uyarı ve uzaklaşma sistemi işlevinin kültürel bağlama hassas bir şekilde düzenleniyor olabileceğini ortaya koymaktadır.

Güvensiz bağlanmada görülen kültürel farkların yanı sıra cinsiyet farkları da önemli bir araştırma konusudur. Geçmiş çalışmalar erkeklerin bağlanma kaçınmasına, kadınların da bağlanma kaygısına görece daha yüksek düzeylerde sahip olduğunu göstermiştir (Brennan, Clark ve Shaver, 1998; Del Guidice, 2011; Kirkpatrick, 1998; Schmitt, 2008). Güvensiz bağlanmadaki bu cinsiyet farkını açıklayabilen bir teorik çerçeve Trivers'ın (1972) ebeveynlik yatırımı teorisidir. Bu teoriye göre kadınların üreme yatırımı (örn., hamilelik, emzirme) erkeklere göre fazla olduğundan daha seçici eş tercihinde bulunma ve o eşi kaybetmeme dürtüsü erkeklere göre fazladır. $\mathrm{Bu}$ asimetri düşünüldüğünde, ortalamada kadınların terk edilmekten daha çok korkması, erkeklerin ise tek bir eşe bağlanma konusunda daha gönülsüz olması beklenebilir. Ancak cinsiyetler arası güvensiz bağlanma farklarının etki büyüklüklerinin görece az olduğu ve her kültürde de rapor edilmediği unutulmamalıdır (Schmitt ve ark., 2003). Güvensiz bağlanmadaki cinsiyet farklılıkları büyük ölçüde sosyal ve ekolojik çevre koşullarından etkilemektedir. Örneğin, yüksek seviyede patojenin olduğu veya fakirliğin yaygın olduğu yüksek stresli çevrelerde güvensiz bağlanma ile ilişkili kısa süreli üreme stratejisi hem kadınlar hem erkekler tarafından daha çok kullanılmaktadır (Gangestad ve Simpson, 2000). Ayrıca daha ağır koşullar getiren ekolojilerde bağlanma kaçınmasında görülen artışın kadınlarda erkeklerde olana göre daha fazla olduğu bulunmuştur (Schmitt ve ark., 2003). Bütün bu bulgular güvensiz bağlanmadaki cinsiyet farklarının çevreden bağımsız düşünülemeyeceğini göstermektedir.

Genel olarak, bağlanma figürlerimizle nasıl ilişki kurduğumuzu inceleyen araştırmaların, yaygın olarak yetersiz ve uyumsuz olarak değerlendirilen güvensiz bağlanan bireylerin bu davranışlarının altında yatan "olası işlevsel avantajları" daha iyi açıklayacak bir şekilde genişlemesi bağlanma yazınına önemli katkıda bulunacaktır. Son yıllarda bu kapsamda yapılan araştırmaların bulguları güvensiz bağlanan bireylerin bir anlamda "kuralın istisnaları" olmadıklarını ve aslında varlığımızı sürdürmede en az güvenli bağlanan bireyler kadar önemli olduklarını göstermektedir. Gelecekteki araştırmaların bu derleme çalışmasında ele alınan yaklaşımlardan da yararlanarak farklı bağlanma yönelimlerini ve bunların diğer psikolojik yapılarla ilişkisini araştırırken güvensiz bağlanmanın öncüllerine ve uyumlayıcı üstünlüklerine yoğunlaşması faydalı olacaktır. 


\section{Kaynaklar}

Ainsworth, M. D. S. (1967). Infancy in Uganda: Infant care and the growth of love. Baltimore: Johns Hopkins University Press.

Aguirre, B. E., Wenger, D. ve Vigo, G. (1998). A test of the emergent norm theory of collective behavior. Sociological Forum, 13(2), 301-311.

Baumeister, R. F. ve Leary, M. R. (1995). The need to belong: Desire for interpersonal attachment as a fundamental human motivation. Psychological Bulletin, 117(3), 497-529.

Belsky, J. (1997). Attachment, mating, and parenting: An evolutionary interpretation. Human Nature, 8(4), 361-381.

Belsky, J. (1999). Modern evolutionary theory and patterns of attachment. J. Cassidy ve P. R. Shaver (Ed.), Handbook of attachment: Theory, research, and clinical applications içinde (141-161). New York: Guilford Press.

Belsky, J., Schlomer, G. L. ve Ellis, B. J. (2012). Beyond cumulative risk: Distinguishing harshness and unpredictability as determinants of parenting and early life history strategy. Developmental Psychology, 48, 662-673. doi: 10.1037/a0024454

Belsky, J., Steinberg, L. ve Draper, P. (1991). Childhood experience, interpersonal development, and reproductive strategy: An evolutionary theory of socialization. Child Development, 62, 647-670. doi: 10.1037/a0024454

Belsky, J., Steinberg, L., Houts, R. M., Halpern-Felsher, B. L. ve the NICHD Early Child Care Research Network (2010). The development of reproductive strategy in females: Early maternal harshness $\rightarrow$ earlier menarche $\rightarrow$ increased sexual risk taking. Developmental Psychology, 46, 120-128. doi: 10.1037/a0015549

Bowlby, J. (1973). Attachment and loss: Vol. II. Separation: Anxiety and anger. New York: Basic Books.

Bowlby, J. (1980). Attachment and loss: Vol. III. Loss: Sadness and depression. New York: Basic Books.

Bowlby, J. (1982). Attachment and loss: Vol. I. Attachment (2. bask1). New York: Basic Books (1. bask1 1969).

Brennan, K. A., Clark, C. L. ve Shaver, P. (1998). Self-report measures of adult romantic attachment. J. A. Simpson ve W. S. Rholes (Ed.), Attachment theory and close relationships içinde (46-76). New York: Guilford.

Bretherton, I. ve Munholland, K. (2008). Internal working models in attachment relationships: Elaborating a central construct in attachment theory. J. Cassidy ve P. R. Shaver (Ed.), Handbook of attachment: Theory, research, and clinical applications
(2. bask1) içinde (102-127). New York, NY: Guilford.

Brewer, M. B. ve Caporael, L. (2006). An evolutionary perspective on social identity: Revisiting groups. M. Schaller, J. Simpson ve D. Kenrick (Ed.), Evolution and social psychology içinde (143-161). New York: Psychology Press.

Caporael, L. R. (1997). The evolution of truly social cognition: The core configurations model. Personality and Social Psychology Review, 1(4), 276-298.

Cassidy, J. (2000). Adult romantic attachments: A developmental perspective on individual differences. Review of General Psychology, 4, 111-131. doi: 10.1037/1089-2680.4.2.111

Cassidy, J. ve Kobak, R. R. (1988). Avoidance and its relation to other defensive processes. In J. Belsky ve T. Nezworski (Ed.), Clinical implications of attachment içinde (300-323). Hillsdale, NJ: Erlbaum.

Charnov, E. L. (1993). Life history invariants. Oxford, UK: Oxford University Press.

Chisholm, J. S. (1993). Death, hope, and sex: Life history theory and the development of reproductive strategies. Current Anthropology, 34, 1-24. doi: $10.1086 / 204131$

Chisholm, J. S. (1996). The evolutionary ecology of attachment organization. Human Nature, 7, 1-38. doi: 10.1007/BF02733488

Del Giudice, M. (2011). Sex differences in romantic attachment: A meta-analysis. Personality and Social Psychology Bulletin, 37, 193-214. doi: 10.1177/0146167210392789

Draper, P. ve Harpending, H. (1982). Father absence and reproductive strategy: An evolutionary perspective. Journal of Anthropological Research, 38(3), 255-273.

Durrett, M. E., Otaki, M. ve Richards, P. (1984). Attachment and the mother's perception of support from the father. International Journal of Behavioral Development, 7, 167-176. doi: 10.1177/016502548400700205

Ein-Dor, T., Mikulincer, M., Doron, G. ve Shaver, P. R. (2010). The attachment paradox: How can so many of us (the insecure ones) have no adaptive advantages? Perspectives on Psychological Science, 5, 123-141. doi: 10.1177/1745691610362349

Ein-Dor, T., Mikulincer, M. ve Shaver, P. R. (2011a). Attachment insecurities and the processing of threat-related information: Studying the scripts involved in insecure people's coping strategies. Journal of Personality and Social Psychology, 101, 78-93. doi: $10.1037 / \mathrm{a} 0022503$

Ein-Dor, T., Mikulincer, M. ve Shaver, P. R. (2011b). Effective reaction to danger: Attachment insecurities 
predict behavioral reactions to an experimentally induced threat above and beyond general personality traits. Social Psychological and Personality Science, 2, 467-473. doi: 10.1177/1948550610397843

Ein-Dor, T. ve Perry, A. (2014). Full house of fears: Evidence that people high in attachment anxiety are more accurate in detecting deceit. Journal of Personality, 82, 83-92. doi: 10.1111/jopy. 12035

Ein-Dor, T. ve Perry-Paldi, A. (2014). Human reaction to threat: Examining the interplay between personality dispositions and situational features. Psychology Research, 4(8), 599-622.

Ellis, B. J. (2004). Timing of pubertal maturation in girls. Psychological Bulletin, 130, 920-958. doi: 10.1037/0033-2909.130.6.920

Feinberg, W. E. ve Johnson, N. R. (2001). The ties that bind: A macro-level approach to panic. International Journal of Mass Emergencies and Disasters, 19(3), 269-295.

Friedman, M., Rholes, W. S., Simpson, J., Bond, M., Dias-Loving, R. ve Chan, C. (2010). Attachment avoidance and the cultural fit hypothesis: A cross-cultural investigation. Personal Relationships, 17, 107-126. doi: 10.1111/j.1475-6811.2010.01256.x

Fox, L., Han, W., Ruhm, C. ve Waldfogel, J. (2012). Time for children: Trends in the employment patterns of parents, 1967-2009. Demography, 50, 1-25. doi: $10.3386 / \mathrm{w} 17135$

Gangestad, S. W. ve Buss, D. M. (1993). Pathogen prevalence and human mate preferences. Ethology and Sociobiology, 14, 89-96. doi: 10.1016/01623095(93)90009-7

Gangestad, S. W. ve Simpson, J. A. (2000). The evolution of human mating: Trade-offs and strategic pluralism. Behavioral and Brain Sciences, 23, 573644. doi: 10.1017/S0140525X0000337X

Griskevicius, V., Delton, A. W., Robertson, T. E. ve Tybur, J. M. (2011). Environmental contingency in life history strategies: Influence of mortality and socioeconomic status on reproductive timing. Journal of Personality and Social Psychology, 100, 241-254. doi: 10.1037/a0021082

Hamilton, W. D. (1964). The genetical evolution of social behaviour: I and II. Journal of Theoretical Biology, 7(1), 1-52.

Harma, M. ve Sümer, N. (2016). Are avoidant wives and anxious husbands unhappy in a collectivist context? Dyadic associations in established marriages. Journal of Family Studies, 22, 63-79. doi: 10.1080/13229400.2015.1024711

Hazan, C. ve Shaver, P. R. (1987). Romantic love conceptualized as an attachment process. Journal of Personality and Social Psychology, 52(3), 511-524.
Hesse, E. (2008). The Adult Attachment Interview: Historical and current perspectives. J. Cassidy ve P. R. Shaver (Ed.), Handbook of attachment: Theory, research, and clinical applications (2. bask1) içinde (552-598). New York: Guilford Press.

Hinde, R. A. (1982). Attachment: Some conceptual and biological issues. C. M. Parkes ve J. Stevenson-Hinde (Ed.), The place of attachment in human behavior içinde (60-70). New York: Basic Books.

Hinde, R. A. ve Stevenson-Hinde, J. (1990). Attachment: Biological, cultural, and individual desiderata. Human Development, 33, 62-72. doi: 10.1159/000276503

Hoff, E., Laursen, B. ve Tardif, T. (2002). Socioeconomic status and parenting. M. H. Bornstein (Ed.), Handbook of parenting: Vol. 2. Biology and ecology of parenting içinde (231-252). Mahwah, NJ: Erlbaum.

Hofstede, G. (2001). Culture's consequences: Comparing values (2. bask1). California: Sage Publications Inc.

James, J. ve Ellis, B. J. (2013). The development of human reproductive strategies: Toward an integration of life history and sexual selection models. J. A. Simpson ve L. Campbell (Ed.), The Oxford handbook of close relationships içinde (771-794). New York: Oxford University Press.

James, J., Ellis, B. J., Schlomer, G. L. ve Garber, J. (2012). Sex-specific pathways to early puberty, sexual debut and sexual risk-taking: Tests of an integrated evolutionary-developmental model. Developmental Psychology, 48, 687-702. doi: 10.1037/a0026427

Kaplan, H. S. ve Gangestad, S. W. (2005). Life history theory and evolutionary psychology. D. M. Buss (Ed.), The handbook of evolutionary psychology içinde (68-95). Hoboken, NJ: Wiley.

Kirkpatrick, L. A. (1998). Evolution, pair-bonding, and reproductive strategies. J. A. Simpson ve W. S. Rholes (Ed.), Attachment theory and close relationships içinde (353-393). New York: Guilford Press.

Koehler, N. ve Chisholm, J. S. (2007). Early psychosocial stress predicts extra-pair copulations. Evolutionary Psychology, 5, 184-201. doi: 10.1177/147470490700500111

Koehler, N. ve Chisholm, J. S. (2009). Early psychosocial stress affects men's relationship length. Journal of Sex Research, 46, 366-374. doi: 10.1080/00224490902773996

Konrath, S. (2012). The empathy paradox: Increasing disconnection in the age of increasing connection. R. Luppicini (Ed.), Handbook of research on technoself: Identity in a technological society içinde (204-228). Hersey, PA: IGI Global. 
Konrath, S. H., Chopik, W. J., Hsing, C. K. ve O'Brien, E. (2014). Changes in adult attachment styles in American college students over time: A meta-analysis. Personality and Social Psychology Review, 18, 1-23. doi: 10.1177/1088868314530516

Konrath, S. H., O'Brien, E. ve Hsing, C. (2011). Changes in dispositional empathy in American college students over time: A meta-analysis. Personality and Social Psychology Review, 15, 180-198. doi: $10.1177 / 1088868310377395$

Lamb, M. E., Thompson, R. A., Gardner, W., Charnov, E. L. ve Estes, D. (1984). Security of infantile attachment as assessed in the Strange Situation: Its study and biological interpretation. Behavioral and Brain Sciences, 7(1), 127-147.

Lavy, S., Bareli, Y. ve Ein-Dor, T. (2015). The effects of attachment heterogeneity and team cohesion on team functioning. Small Group Research, 46, $27-$ 49. doi: $10.1177 / 1046496414553854$

Main M. (1981). Avoidance in the service of attachment. K. Immelmann, G. Barlow, M. Main, ve L. Petrinovich (Ed.), Behavioral development içinde (651-693). Cambridge, UK: Cambridge University Press.

Main, M. (1990). Cross-cultural studies of attachment organization: Recent studies, changing methodologies, and the concept of conditional strategies. Human Development, 33, 48-61. doi: $10.1159 / 000276502$

Main M. ve Solomon J. (1986). Discovery of a new, insecure-disorganized/disoriented attachment patter. M. Yogman ve T. B. Brazelton (Ed.), Affective development in infancy içinde (95-124). Norwood, NJ: Ablex.

Maitner, A. T., Mackie, D. M. ve Smith, E. R. (2006). Evidence for the regulatory function of intergroup emotion: Implementing and impeding intergroup behavioral intentions. Journal of Experimental Social Psychology, 42, 720-726. doi: 10.1016/j. jesp.2005.08.001

Mikulincer, M., Birnbaum, G., Woddis, D. ve Nachmias, O. (2000). Stress and accessibility of proximity-related thoughts: Exploring the normative and intraindividual components of attachment theory. Journal of Personality and Social Psychology, 78, 509-523. doi: 10.1037//0022-3514.78.3.509

Mikulincer, M., Gillath, O. ve Shaver, P. R. (2002). Activation of the attachment system in adulthood: Threat-related primes increase the accessibility of mental representations of attachment figures. Journal of Personality and Social Psychology, 83, 881-895. doi: 10.1037//0022-3514.83.4.881

Mikulincer, M. ve Shaver, P. R. (2008). Adult attachment and affect regulation. J. Cassidy ve P. R. Shaver (Ed.), Handbook of attachment: Theory, research, and clinical applications içinde (503-531). New York: Guilford Press.

Mikulincer, M. ve Shaver, P. R. (2007). Attachment in adulthood: Structure, dynamics, and change. New York: Guilford Press.

Proulx, G. (2003). Researchers learn from World Trade Center survivors' accounts. Construction Innovation, 8(1), 1-3.

Rom, E. ve Mikulincer, M. (2003). Attachment theory and group processes: The association between attachment style and group-related representations, goals, memories, and functioning. Journal of Personality and Social Psychology, 84, 1220-1235. doi: 10.1037/0022-3514.84.6.1220

Sagi, A., van IJzendoorn, M. H., Aviezer, O., Donnell, F. ve Mayseless, O. (1994). Sleeping out of home in a kibbutz communal arrangement: It makes a difference for infant -mother attachment. Child Development, 65(4), 992-1004.

Sakman, E. (2016). Functionality of insecure attachment in cultural context as an early alarm and escape system. (Yayımlanmamış doktora tezi). Orta Doğu Teknik Üniversitesi, Ankara.

Schmitt, D. P. (2008). Evolutionary perspectives on romantic attachment and culture: How ecological stressors influence dismissing orientations across genders and geographies. Cross-Cultural Research, 42, 220-247. doi: 10.1177/1069397108317485

Schmitt, D. P. (2010). Romantic attachment from Argentina to Zimbabwe: Patterns of adaptive variation across contexts, cultures, and local ecologies. P. Erdman ve K-M Ng (Ed.), Attachment: Expanding the cultural connections içinde (211-226). New York: Routledge/Taylor \& Francis Group.

Schmitt, D. P., Alcalay, L., Allesenworth, M., Allik, J., Ault, L., Austers, I., ... Zupanèiè, A. (2003). Are men universally more dismissing than women? Gender differences in romantic attachment across 62 cultural regions. Personal Relationships, 10, 307-331. doi:10.1111/1475-6811.00052

Schmitt, D. P., Alcalay, L., Allensworth, M., Allik, J., Ault, L., Austers, I., . . . ZupanÈì̀, A. (2004). Patterns and universals of adult romantic attachment across 62 cultural regions: Are models of self and of other pancultural constructs? Journal of Cross-Cultural Psychology, 35, 367-402. doi: 10.1177/0022022104266105

Selcuk, E., Günaydin, G., Sumer, N., Harma, M., Salman, S., Hazan, C., ... Ozturk, A. (2010). Self-reported romantic attachment style predicts everyday maternal caregiving behavior at home. Jour- 
nal of Research in Personality, 44, 544-549. doi: 10.1016/j.jrp.2010.05.007

Sime, J. D. (1983). Affiliative behavior during escape to building exits. Journal of Environmental Psychology, 3, 21-41. doi: 10.1016/S02724944(83)80019-X

Simpson, J. A. ve Belsky, J. (2008). Attachment theory in modern evolutionary perspective. J. Cassidy ve P. R. Shaver (Ed.), Handbook of attachment: Theory, research, and clinical applications (2. bask1) içinde (131-157). New York: Guilford Press.

Smith, E. R. (1993). Social identity and social emotions: Toward new conceptualizations of prejudice. D. M. Mackie ve D. L. Hamilton (Ed.), Affect, cognition, and stereotyping: Interactive processes in group perception içinde (297-315). San Diego, CA: Academic Press.

Sober, E. ve Wilson, D. S. (1998). Unto others: The evolution and psychology of unselfish behavior. Cambridge, MA: Harvard University Press.

Solak, N., Sakman, E., Sümer, N. ve Schmitt, D. (2017). Familial stressors as risk factors for attachment anxiety and avoidance. Hakem değerlendirmesinde: Personal Relationships

Stearns, S. C. (1992). The evolution of life histories. Oxford, England: Oxford University Press.

Sümer, N. (2015). Attachment avoidance harms friendship quality and life satisfaction among Turkish children. M. Demir (Ed.), Friendship and happiness: Across the life-span and cultures içinde (253-274). Dordrecht: Springer Publishing.

Sümer, N. ve Kağıtçıbaşı, Ç. (2010). Culturally relevant parenting predictors of attachment security: Perspectives from Turkey. P. Erdman ve K-M. Ng (Ed.), Attachment: Expanding the cultural connections içinde (157-180). New York: Routledge/Taylor \& Francis Group.

Trivers, R. (1972). Parental investment and sexual selection. B. Campbell (Ed.), Sexual selection and the descent of man, 1871-1971 içinde (136-179). Chicago: Aldine.

True, M. M., Pisani, L. ve Oumar, F. (2001). Infant-mother attachment among the Dogon of Mali. Child Development, 72(5), 1451-1466.

Twenge, J. M. (1997). Changes in masculine and feminine traits over time: A meta-analysis. Sex Roles, 36, 305-325. doi: 10.1007/BF02766650

Twenge, J. M. (2006). Generation Me: Why today's young Americans are more confident, assertive, entitled-and more miserable than ever before. New York, NY: Free Press.

Twenge, J. M., Konrath, S., Foster, J. D., Campbell, W. K. ve Bushman, B. J. (2008). Egos inflating over time:
A cross-temporal meta-analysis of the Narcissistic Personality Inventory. Journal of Personality, 76, 875-902. doi: 10.1111/j.1467-6494.2008.00507.x

van Uzendoorn, M. H., Goldberg, S., Kroonenberg, P. M. ve Frenkel, O. J. (1992). The relative effects of maternal and child problems on the quality of attachment: A meta-analysis of attachment in clinical samples. Child Development, 63(4), 840-858.

van IJzendoorn, M. H. ve Kroonenberg, P. M. (1988). Cross-cultural patterns of attachment: A meta-analysis of the Strange Situation. Child Development, 59, 147-156. doi: 10.2307/1130396

van IJzendoorn, M. H. ve Sagi-Schwartz, A. (2008). Cross-cultural patterns of attachment: Universal and contextual dimensions. J. Cassidy ve P. R. Shaver (Ed.), Handbook of attachment: Theory, research, and clinical applications (2. bask1) içinde (880-905). New York: Guilford Press.

Zeifman, D. ve Hazan, C. (1997). Attachment: The bond in pair-bonds. J. A. Simpson ve D. T. Kenrick (Ed.), Evolutionary social psychology içinde (237263). Hillsdale, NJ: Erlbaum.

Zimmer-Gembeck, M. J. ve Helfand, M. (2008). Ten years of longitudinal research on U.S. adolescent sexual behavior: Developmental correlates of sexual intercourse, and the importance of age, gender and ethnic background. Developmental Review, 28, 153-224. doi: 10.1016/j.dr.2007.06.001 


\section{Summary Why is Insecure Attachment Prevalent? Insecure Attachment as an Early Alarm and Escape System}

\author{
Ezgi Sakman \\ Bilkent University
}

The attachment behavioral system is an evolutionarily adaptive regulatory device which adjusts proximity to supportive others (i.e., attachment figures), hence ensures protection and survival (Bowlby, 1969/1982, 1973, 1980). It functions with individual differences stemming from experiences with significant others: While if the attachment figure is consistent in providing the much needed sensitive caregiving, the individual develops a sense of security and connectedness that leads to attachment security; if the attachment figure fails to fulfill these basic attachment needs, the individual develops attachment insecurity. Insecure attachment can result due to two distinct mechanisms: When the attachment figure is constantly harsh, rejecting, and unwilling to provide warm care, the individual develops compulsive self-reliance, and as a result cultivates attachment avoidance; when the attachment figure is inconsistent, insensitive, or intrusive in caregiving, the individual intensifies proximity seeking attempts, and consequently develops attachment anxiety. Mikulincer and Shaver (2007) delineated these mechanisms in their model of attachment-system functioning and dynamics.

Attachment Theory has generated an immense body of research and the common theme of this plethora of findings seems to be that secure attachment is the "good" attachment style to have: Securely attached individuals report higher life quality and happiness, they are more successful in close relationships, and they perform better professionally. Conversely, research findings have consistently linked insecure attachment with adverse outcomes, such as problematic close relationships, dysfunctional ways of coping with stress, low life satisfaction and happiness (see Mikulincer \& Shaver, 2007 for a review). Despite this apparent abundance of maladaptive consequences and lack of advantages of insecure attachment, not only it subsists, it is actually quite prevalent: Ample research shows that nearly half of the population exhibits insecure attachment tendencies across stages of development, cultures, and measurement techniques (see

\author{
Nebi Sümer \\ Sabanc1 University
}

Hesse, 2008; van IJzendoorn \& Sagi-Schwartz, 2008 for reviews). It seems odd that insecure attachment would survive years of selection pressures and still be just as widespread as secure attachment if it did not provide humans with any adaptive advantages. Ein-Dor, Mikulincer, Doron, and Shaver (2010) have pointed out to this interesting conundrum and called it the attachment paradox.

Despite the mainstream attachment research mainly focusing on the benefits of secure attachment, some scholars have put forward the idea that insecure attachment may carry adaptive value in the domains of reproductive fitness and group survival (e.g., Belsky, Steinberg, \& Draper, 1991; Chisholm, 1996; and Ein-Dor et al., 2010). These evolutionary accounts of the attachment theory aim to answer the question of why different attachment patterns have developed, rather than how (as traditional attachment research has done in the past). In the present review, first the life history models of attachment that have proposed that insecure attachment may have evolved to increase reproductive fitness will be discussed. Then the social defense theory, which posits that insecure attachment may have adaptive advantages for group survival under conditions of imminent threat, will be addressed.

\section{The Adaptive Value of Insecure Attachment from a Reproductive Fitness Perspective: The Life History Models of Attachment}

The theoretical frameworks that put forward the idea that the attachment system may have evolved not only to ensure survival in childhood, but also as a mechanism that promotes reproductive fitness in adulthood vis-à-vis the conditions of the environment (Belsky et al., 1991; Chisholm, 1996; see also Ellis, 2004; Kirkpatrick, 1998; Zeifman \& Hazan, 1997) are largely influenced by the life history theory (Charnov, 1993; Stearns, 1992). The life history theory posits that all organisms

Address for Correspondence: Ph.D. Ezgi Sakman, Bilkent University, Department of Psychology, Bilkent / Ankara

E-mail: ezgi.sakman@bilkent.edu.tr 
have finite resources and face the challenge of allocating these scarce resources between the fundamental goals of survival/growth and reproduction. The core trade-offs that individuals face are to decide whether to reproduce now or in the future, whether to maximize the quality or the quantity of the offspring, and whether to invest more in mating or in parenting. The theory predicts that natural selection favors those mechanisms which achieve the optimal allocation of the resources among these competing goals in accordance with the constraints set by the ecological setting; hence maximize reproductive success (see Kaplan \& Gangestad, 2005 for a review).

Inspired the life history theory, Belsky and colleagues (1991) put forward a model proposing that the social and ecological context (e.g., environmental stress, inadequate resources, marital discord) affects parenting (e.g., the sensitivity and responsiveness of caregiving, overall parenting investment), which impacts the psychological and behavioral development of the child (e.g., attachment pattern and internal working models), which in turn influences the somatic development (e.g., sexual maturation), which finally shapes the mating strategy (e.g., short-term vs. long-term, high vs. low quality offspring) of her or him as an adult. Belsky and colleagues argue that children who learn in their familial environment that resources are scarce and/or unpredictable, people are untrustworthy and relationships are unstable, develop insecure attachment style, reach sexual maturity early, adopt a reproductive strategy that favors early-onset, short-term, and multiple pair bonds, and offer low parental investment to their offspring. Conversely, children who have early experiences which indicate that resources are constantly available, people are trustworthy and relationships are rewarding, develop secure attachment style, sexually mature later, employ a reproductive strategy that favors deferred, long-term and exclusive pair bonds, and offer high parental investment to their offspring. Belsky and colleagues regard both strategies as biologically sound in the sense that they both develop as adaptations to the conditions of the environment.

In another model inspired by the life history theory, Chisholm $(1993,1996)$ argues that the harshness of the environment, as mirrored in local mortality rates, cue the children to develop adaptive attachment styles via the level of parental investment. In ecologies with low mortality rates, securely attached children enjoy longer parental investment, hence they are able to allocate their resources to growth and delay mating; when they do eventually reproduce, they seek long-term mates and offer high parental investment themselves. In contrast, under harsh environmental conditions, as children high on attachment avoidance are forced to become independent at an early age by their rejecting parents, they allocate their scarce resources to early-onset reproduction and adopt a short-term mating strategy. Children high on attachment anxiety do not cease their attempts to extract resources from their inconsistent parents, but funnel these resources not to development but to earlier reproduction. Also within this perspective, attachment security is not regarded as the sole functional attachment orientation; but development of the appropriate attachment tendency is seen as an adaptation to the local environment, which manifests itself in increased reproductive fitness.

\section{The Adaptive Value of Insecure Attachment from a Group Survival Perspective: The Social Defense Theory}

The life history models of attachment have received extensive empirical support (for recent reviews, see James \& Ellis, 2013; Simpson \& Belsky, 2008). Yet they overlook the fact that even though insecure attachment may carry adaptive value in the domain of reproductive fitness, it is still associated with adverse outcomes on the individual level. In an effort to complement this perspective, Ein-Dor and colleagues (2010) put forward their social defense theory and argued that another adaptive advantage of insecure attachment may lie at the group level under conditions of threat. They base their argument on Hamilton's (1964) kin selection theory and Sober and Wilson's (1998) multilevel selection theory, which suggest that an individual's total (inclusive) fitness is determined not only by his or her own reproductive output, but also by the inclusion of the reproductive success of kin with whom genes are shared.

According to the social defense theory, while attachment security is beneficial to the group under normal circumstances, the relative adaptive advantages of attachment insecurity surface under conditions of emergent threat (Ein-Dor et al., 2010). Ein-Dor and colleagues proposed that people high on attachment anxiety may serve the survival of the group by being sentinels, who can detect early and ambiguous signs of an imminent danger and alert the other members, as a result of their hypervigilance to threat and stress cues which stem from their chronically hyperactivated attachment systems. Individuals high on attachment avoidance are also argued to be functional for the group because they are more likely to develop rapid fight-or-flight reactions to danger in order to protect themselves and be quick to detect and use escape routes as they are chronically inclined to flee. These cognitive schemas and action tendencies are argued to be beneficial also for the rest of the group as people are likely to follow these members high on attachment avoidance through the escape routes they discovered or created. Ein-Dor and colleagues put their 
ideas to empirical test and showed that while individuals high on attachment anxiety have easier cognitive access to the sentinel script (Ein-Dor, Mikulincer, \& Shaver, 2011a; Ein-Dor \& Perry-Paldi, 2014), and more likely to act in accordance with it under conditions of threat (EinDor, Mikulincer, \& Shaver, 2011b); individuals high on attachment avoidance more readily activate the rapid fight-or-flight schema and engage in behaviors compatible with it when they perceive danger.

\section{Discussion}

Despite the impressive amount and eminence of research in the domain of attachment, possible adaptive functions of its insecure form have been widely neglected. Yet, investigating and understanding the adaptive value of insecure attachment may be especially important as recent research findings suggests that its prevalence may be on the rise (Konrath, Chopik, Hsing, \& O’Brien, 2014).

When Ein-Dor and colleagues' (2010) group survival perspective and Belsky and colleagues' (1991) and Chisholm's (1993, 1996) reproductive fitness perspective to functionality of different attachment tendencies are put together, they complement each other and why insecure attachment, which has been solidly associated with adverse individual outcomes, has been able to survive years of selection pressures becomes more clear: It serves as armor in harsh ecologies and under conditions of emerging threat by leading the individual to adaptive reproductive strategies and survival tactics, contingent to the demands of the environment, and this results in increased changes of successful reproduction and survival, both as individuals and as groups.
The study of functionality of attachment insecurity could also be carried to the next level of analysis, the cultural level. Studies have documented that although attachment security emerges as a universal norm (van IJzendoorn \& Sagi-Schwartz, 2008), the pattern of adult insecure attachment vary greatly across cultures: Whereas attachment anxiety is relatively common in collectivist cultures, attachment avoidance is more prevalent in individualist cultures (see Schmitt, 2010). Building on the cultural fit hypothesis, which argues that the prevalent form of attachment insecurity is associated with less adverse outcomes (Friedman et al., 2010), Sakman (2016) recently hypothesized that the more prevalent form of insecure attachment might have higher adaptive value in the specific cultural context. The results of the correlational and experimental studies carried out to test this hypothesis showed that while anxious sentinel behaviors are regarded as the more functional strategy in threat situations under a collectivist cultural mindset, which is more strongly related to attachment anxiety; avoidant fightor-flight behaviors are regarded as the more functional course of action in situations of emergency under an individualist cultural mindset, which is more strongly related to attachment avoidance. These results suggest that the early alarm and escape function of insecure attachment may be regulated in a culturally sensitive manner.

Overall, one could argue that the dominant research perspective in how we relate to significant others should be broadened by the potential strengths and contributions of insecurely attached individuals, who have been widely regarded as deficient and poorly adapted. Mounting evidence suggests that not only they are not dissonant to the norm, they may be just as important as the secure ones in forwarding our existence. 